\title{
REACTIVE EXTRACTION OF TARTARIC ACID
}

\author{
Natalia Marchitan \\ Department of Industrial and Ecological Chemistry, Faculty of Chemistry and Chemical Technology, \\ Moldova State University, 60 A. Mateevici str., MD 2009, Chisinau, Republic of Moldova \\ E-mail: n_marchitan@yahoo.com,(+373 22) 577796
}

\begin{abstract}
The present paper describes the results of reactive extraction of tartaric acid in model systems, which can be used for its separation from secondary wine products. As extractant have been used a normal/isododecyl mixed secondary amine Amberlite LA-2. The following parameters of the separation process have been varied: nature of diluent and modifier; modifier concentration; concentration, temperature and $\mathrm{pH}$ of the tartaric acid solution and the stirring time, and the work intervals have been established. It was concluded that in determinated conditions the extent of tartaric acid extraction attains value $85-95 \%$.
\end{abstract}

Keywords: reactive extraction, tartaric acid, Amberlite LA-2.

\section{Introduction}

Liquid extraction has been used already for a very long time for separation of metals from production or waste water streams [1-4]. It is an efficient, economical, and environmentally friend method for the recovering of different compounds from waste water, for separation of some biologically active products from fermentation liquids, for extraction of some carboxylic acids [5-14] etc.

Extraction with conventional solvents such as alcohols and ketones are not efficient when applied to dilute carboxylic acid solutions because of the low aqueous activity of carboxylic acids resulting in low distribution coefficients. The strong amine interaction with the acid allows for formation of acid-amine complexes and thus provides for high distribution coefficients. When using amine extragents, a proton transfer occurs during the extraction and the acid prevails in the organic phase as an amine-acid ion pair complex [12].

The difference between the two extraction techniques is due to the appearance of a hydrophobic complex, which is the product of the interfacial chemical reaction between solute and extractant [10].

Primary and secondary amines are stronger bases than tertiary amines and in many cases are also stronger than the anion of the extracted carboxylic acid. These strong bases protonate, therefore, even in equilibrium with solutions, the $\mathrm{pH}$ of which is too high to allow considerable amounts of undissociated carboxylic acids. In that sense carboxylic acid extraction by amine more basic than the anion of the extracted acid (at $\mathrm{pH}<\mathrm{pK}_{\mathrm{a}}$ ), nearly complete protonation takes place to reach stoichiometric extraction through ion-pair formation with dissociated acid molecules. In equilibrium with aqueous phases of high $\mathrm{pH}\left(\mathrm{pH}>\mathrm{pK}_{\mathrm{a}}\right)$ ion-pair formation is the dominating mechanism [15].

In this paper the reactive extraction of tartaric acid from aqueous solution with Amberlite LA-2 was examineted. The separation efficiency depends on solute physical and chemical characteristics (hydrophobicity, acidity), extractant proprieties (reactivity, the ability to form hydrophobic compounds with the solute) and process conditions ( $\mathrm{pH}$-values, concentration of solute, mixing time, temperature of aqueous solution). Thus, the mentioned factors constitute the subject of this study.

\section{Experimental Section}

Materials. The aqueous phase was prepared by dissolving tartaric acid (Reahim, Russia) in distilled water. The initial concentration of tartaric acid solution was $1,56 \mathrm{~g} / \mathrm{dm}^{3}$. Several solvents were used as inert diluents for organic phase - benzene, chloroform, carbon tetrachloride, kerosene, butyl acetate, heptane, methyl isobutyl ketone (MIBK), n-dodecane, 1-butanol, 1-octanol, 1-decanol (all from Sigma-Aldrich, Germany). The last two alcohols also were used as modifiers. The organic phase was prepared by dissolving Amberlite LA-2 (Sigma-Aldrich, Germany) in diluent and adding modifier. The concentration of Amberlite LA-2 in organic phase was $16,62 \mathrm{~g} / \mathrm{dm}^{3}$. Glacial acetic acid (Reactivul, Romania) and sodium metavadanate (Reahim, Russia) were used for determination of tartaric acid concentration, hydrochloric acid (HaricovPromHim, Ukraine) and sodium hydroxide (Chimicomplex, Romania) for $\mathrm{pH}$ value adjustment.

Procedure. The experiments were carried out in $200 \mathrm{~cm}^{3}$ glass flasks. Equal volumes of aqueous phase and organic phase $\left(50 \mathrm{~cm}^{3}\right.$ of each) were mixed by universal stirrer type WU-4 (Premed, Poland) for $15 \mathrm{~min}$ at room temperature, time sufficient to attain equilibrium. The obtained mixtures were let for phase separation for 15-30 min, in same cases it was used centrifugal separator. The process development has been followed by determination the solute concentration in the initial and in the final solution. For the calculation of the solute concentration in the solvent phase mass transfer balance was used. 
Methods. Concentration determination of tartaric acid was realized by photocolorimetric method on colorimeter (Zomz, Russia). For measurements $5 \mathrm{~cm}^{3}$ of analyzed solution were passed into $50 \mathrm{~cm}^{3}$ flask, $4 \mathrm{~cm}^{3}$ of sodium metavanadat solution $(5 \%)$ and $1 \mathrm{~cm}^{3}$ of glacial acetic acid were added, then flask was fitted with distilled water. Obtained solution is left for 15-20 min at dark for the formation of the stable colour in $24 \mathrm{~h}$. Measurements were done at $525 \mathrm{~nm}$ wave length (green filter) in cells with $20 \mathrm{~mm}$ working side length, against a blank similarly prepared without tested solution [16].

Definition of Characteristic Parameters. The extraction is represented by the extent of extraction $\eta(\%)$ and the distribution coefficient D:

$$
\begin{gathered}
\eta=\frac{V_{i n} C_{i n}-V_{e q} C_{e q}}{V_{i n} C_{i n}} \cdot 100 \\
D=\frac{C_{e q(o)}}{C_{e q(a q)}}
\end{gathered}
$$

where $\mathrm{V}$ - volume of the phase, $\mathrm{cm}^{3} ; \mathrm{C}$ - concentration of tartaric acid (of undissociated molecules and of tartaric anions) $\mathrm{g} / \mathrm{dm}^{3}$, index in - initial solution, index $e q$ - solution after reaching equilibrium, index $o$ - organic phase, and index $a q-$ aqueous phase.

\section{Theory}

The general interfacial equilibrium that is established in the reaction between organic oxyacids and Amberlite LA-2 is following:

$$
\mathrm{mR}(\mathrm{COOH})_{\mathrm{n}(\mathrm{aq})}+\mathrm{pQ}_{(\mathrm{o})} \longleftrightarrow\left[\mathrm{R}(\mathrm{COOH})_{\mathrm{n}}\right]_{\mathrm{m}} \cdot \mathrm{Q}_{\mathrm{p}(\mathrm{o})}
$$

where $\mathrm{R}(\mathrm{COOH})_{\mathrm{n}}$ represent the oxyacid ( $\mathrm{n}=2$ for tartaric acid), and $\mathrm{Q}-$ Amberlite LA-2.

Depending on molar ratio between the components, tartaric acid and extraction agent, three types of chemical inter-phase reactions used for reactive extraction may be distinguished:

1) in the case of m:p proportion close to 1, the tartaric acid and extraction agent form the hydrophobic complex in a equimolar proportion (formation of an ion-pair):

$$
\mathrm{R}(\mathrm{COOH})_{\mathrm{n}(\mathrm{aq})}+\mathrm{Q}_{(\mathrm{o})} \rightleftarrows \mathrm{R}(\mathrm{COOH})_{\mathrm{n}} \cdot \mathrm{Q}_{(\mathrm{o})}
$$

2 ) in the case of molar proportion between the carboxylic acid and the extraction agent much lower than 1 $(\mathrm{m}: \mathrm{p}<<1)$, reactive extraction results in the formation of particular complexes $\mathrm{R}(\mathrm{COOH})_{\mathrm{n}} \cdot \mathrm{Q}_{\mathrm{n}}$ in the organic phase:

$$
\mathrm{R}(\mathrm{COOH})_{\mathrm{n}(\mathrm{aq})}+\mathrm{nQ}_{(\mathrm{o})} \rightleftarrows \mathrm{R}(\mathrm{COOH})_{\mathrm{n}} \cdot \mathrm{Q}_{\mathrm{n}(\mathrm{o})}
$$

3 ) in the case of reactive extraction in nonpolar solvents (e.g. butyl acetate) of existent high initial concentrations of oxyacids in aqueous solutions, a third phase is possible to appear, representing a stable emulsion, with a high content of acid complexes, insoluble in aqueous phase as well as in the organic one:

$$
\mathrm{mR}(\mathrm{COOH})_{\mathrm{n}(\mathrm{aq})}+\mathrm{Q}_{(\mathrm{o})} \rightleftarrows\left[\mathrm{R}(\mathrm{COOH})_{\mathrm{n}}\right]_{\mathrm{m}} \cdot \mathrm{Q}_{(\mathrm{o})}
$$

Analysis of the individual mechanism of tartaric acid reactive extraction shows that at concentrations lower than $7,6 \mathrm{~g} / \mathrm{dm}^{3}$ the reactive extraction takes place according to mechanism $(2)-\mathrm{R}(\mathrm{COOH})_{2} \cdot \mathrm{Q}_{2}$. At the rise of tartaric acid concentration there establishes an intermediate mechanism between theoretic mechanisms (1) and (2). This phenomenon may be explained by formation of tartaric acid specific dimmers. Accordingly, one molecules of Amberlite LA-2 extracts more than one molecule of tartaric acid [6-9, 11].

Moreover, in low concentration domain, for a molar ratio between solute and extractant below 1 , the separation occurs mainly by reactive extraction. Contrarily, at molar ratio higher than 1 , the contribution of the physical extraction becomes considerable [10].

\section{Results and Discussion}

Generally, the distribution coefficients of carboxylic acids between aqueous and organic phases, in absence of the extractants, are very low, being higher in polar solvents. This phenomenon is the result of acid dissociation in aqueous solutions because the formed ionic species having a low solubility especially in non-polar solvents [10].

The type of diluent and its concentration in the mixture extractant-diluent have an important effect on the distribution coefficients because the diluent affects basicity of the amine and the stability of the ion-pair complex formed and consequently its extracting power [12].

In this study were used next nonpolar diluents: kerosene, carbon tetrachloride, benzene, dodecane, and heptane; and polar diluents: chloroform, 1-butanol, methyl isobutyl ketone (MIBK) and butyl acetate. The organic 
solution of amine in 1-octanol and 1-decanol were used for separation of tartaric acid. All tests were done using Amberlite LA-2 as extracting reagent.

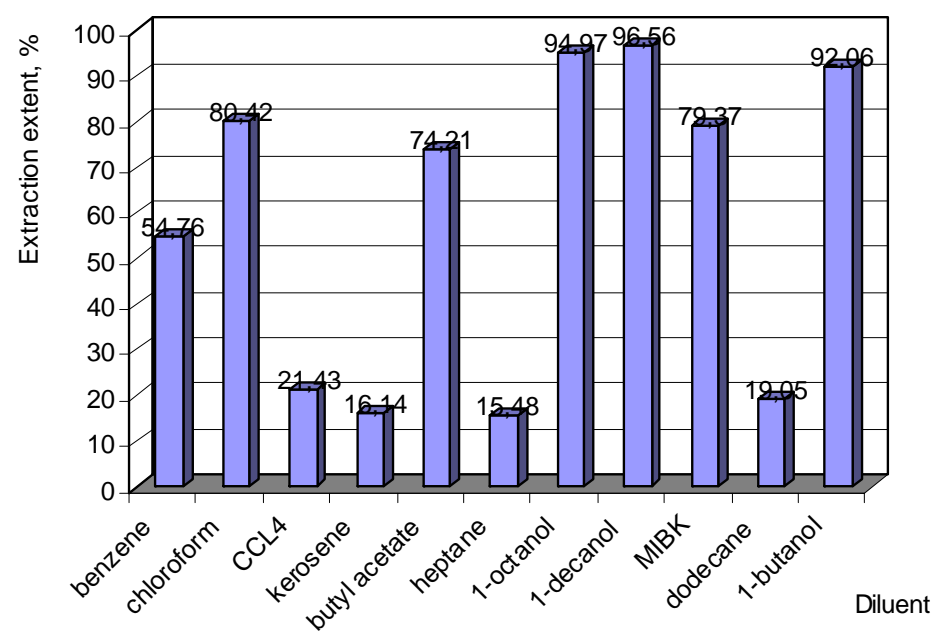

Fig. 1. The influence of diluents on efficiency of the tartaric acid extraction from aqueous phase

The best extraction efficiency was gained for 1-octanol, 1-decanol, and 1-butanol, but using of these solvent caused stable emulsions formation. The same effect was observed in case of dodecane. Thus, were selected benzene, chloroform, butyl acetate and MIBK.

The role of diluent is not only to improve the physical properties of the extraction system, but also removes the interaction product. In the presence of modifier, the inert diluent may enhance its extraction ability as a solvent. Addition of a modifier, such as a high molecular weight alcohol, to overcome third phase and emulsion formation in the system was necessary in case of resulting high concentration of the acid-amine complex in the organic phase $[1,13]$.

1-octanol and 1-decanol were tested as modifier by their separate addition of $\left(10 \mathrm{~cm}^{3}, 20 \% \mathrm{v} / \mathrm{v}\right)$ in organic phase.

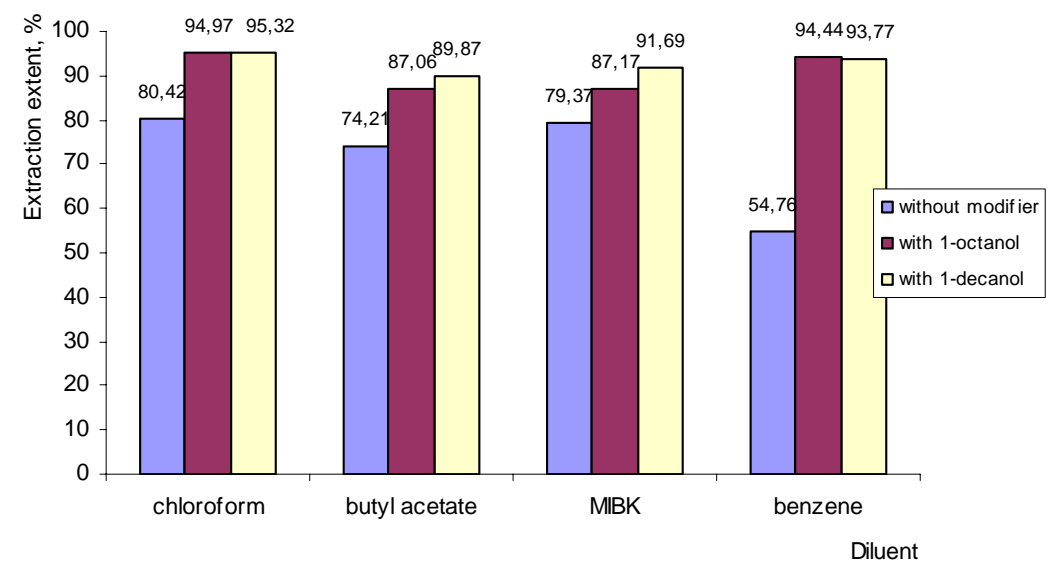

Fig. 2. The influence of the modifiers (10 \%) on efficiency of the tartaric acid extraction from aqueous phase

Fig. 2 shows that 1-octanol and 1-decanolul increased the tartaric acid removal efficiency of organic solution. The results are very similar, thus both modifiers can be used for practical application.

In next studies MIBK wasn't used as solvent because of stability of its formed emulsion (separation time of the phases minimum $90 \mathrm{~min}$ ), and benzene because of its toxicity. The chloroform and butyl acetate were selected as diluents for preparing the amine solution.

It was studied the dependence between the efficiency of tartaric acid extraction and the modifier's concentration in organic solution, which was varied from $2 \%(\mathrm{v} / \mathrm{v})$ to $50 \%(\mathrm{v} / \mathrm{v})$.

In figure 3 can be seen that for a good extraction of tartaric acid the concentration of 1-octanol as modifier should be $10 \%$ in chloroform solution, and $20 \%$ in butyl acetate solution. The 1-octanol concentration higher that $30 \%$ increased tartaric acid extraction just with $2-3 \%$, but made phase separation time after stirring much longer. 


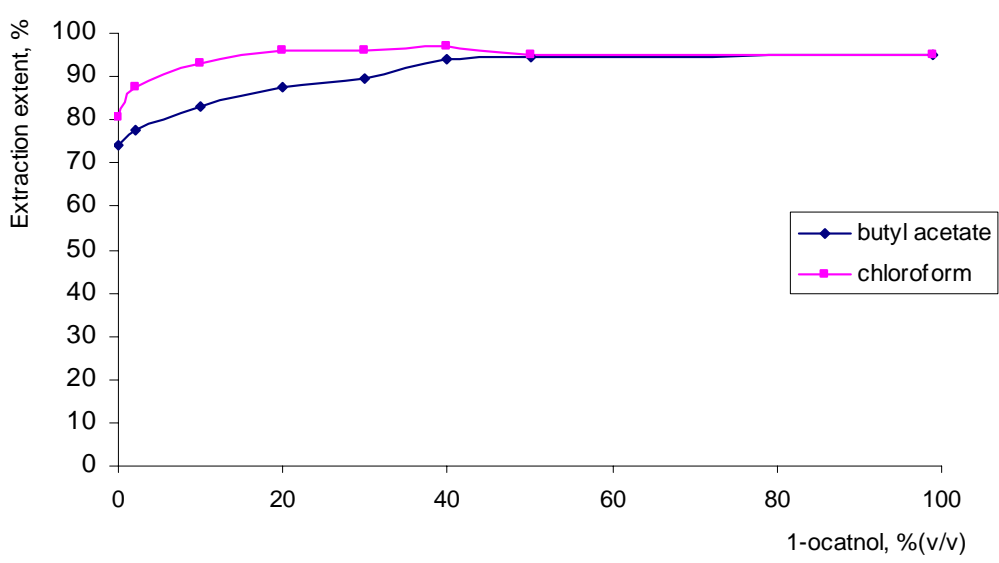

Fig. 3. The effect of 1-octanol concentration on the extraction extent of tartaric acid from aqueous phase

Figure 4 reflects the increase in the extraction extent at the same time with the concentration of tartaric acid in the initial solution, which is due to the lowering of the $\mathrm{pH}$ of the aqueous solution upon elevation of the concentration of tartaric acid. The concentration of tartaric acid was varied from $0,5 \mathrm{~g} / \mathrm{dm}^{3}$ to $10 \mathrm{~g} / \mathrm{dm}^{3}$. In this way, the highest efficiency of separation process was observed for organic solutions of amine in butyl acetate at tartaric acid concentration of $2-3 \mathrm{~g} / \mathrm{dm}^{3}$, and $0,5-2 \mathrm{~g} / \mathrm{dm}^{3}$ for solutions of amine in chloroform.

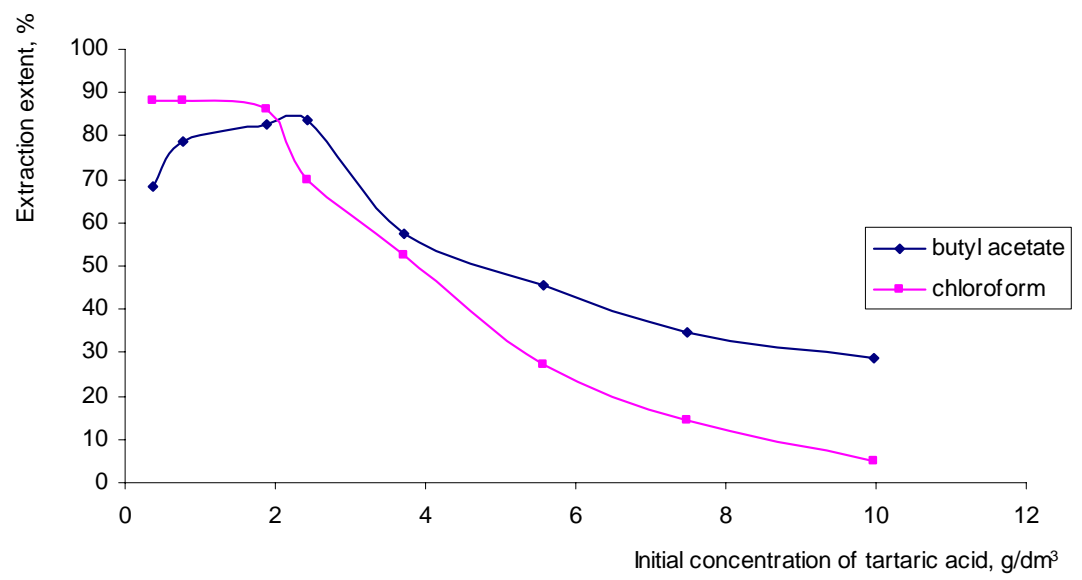

Fig. 4. The effect of the tartaric acid concentration in aqueous solution on its using 1-octanol (10 \%) as modifier

The complexation reactions in the organic phase involve proton transfer or hydrogen-bond formation and are thus expected to be exothermic. Moreover, formation of a complex makes the system more ordered and, therefore decreases the entropy. Thus, as the temperature is increased, the amount of tartaric acid extracted decreases [11, 17].

To find the optimal extraction temperature value the determinations were made in interval from $25{ }^{\circ} \mathrm{C}$ to 75 ${ }^{0} \mathrm{C}$, the last one is the temperature of obtained vinasses after wine or grape must distillation, the other secondary wine produces obtained at lower temperatures. It must be mentioned that for the system which contents chloroform as solvent the higher temperature was $50{ }^{\circ} \mathrm{C}$ (boiling point of chloroform $61{ }^{\circ} \mathrm{C}$ ). It was shown that the efficiency of the tartaric acid separation process from model solution is constant until $35^{\circ} \mathrm{C}$, and after that decreases.

The physical extraction is controlled by the system components diffusion only. For the reactive extraction, a new resistance appears, namely the resistance induced by the interfacial chemical reaction between solute and extractant (the extraction degree increases).

The relative participation of physical extraction increases with rotation speed. In the same time, the evolution of the mass flows with rotation speed for reactive extraction indicated two variation regions corresponding to the diffusional (the increase of the mass flow with rotation speed) and kinetic region (the constant level of mass flows beside the rotation speed increase), respectively [10]. 


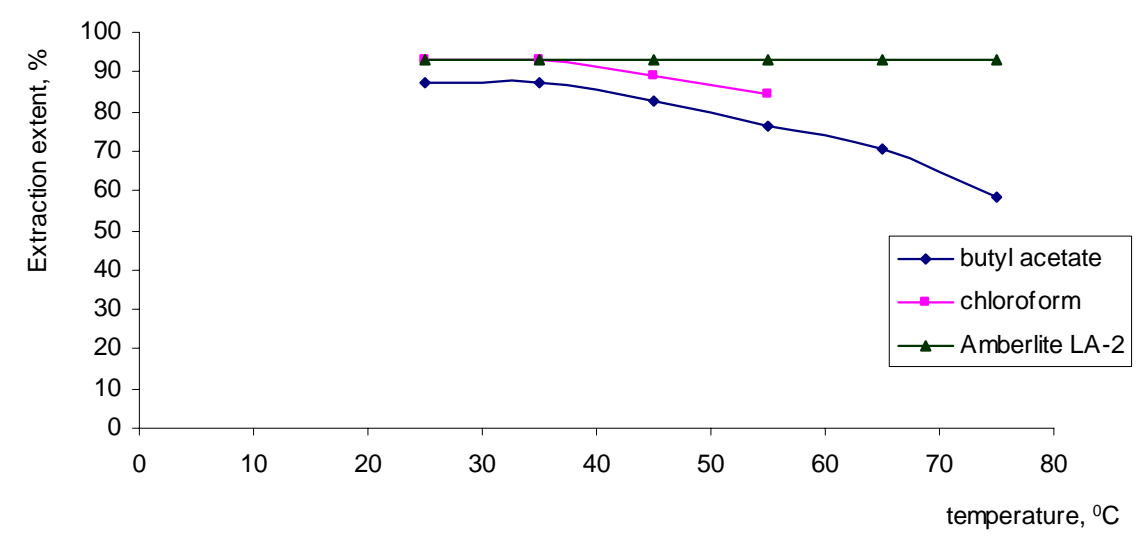

Fig. 5. The influence of temperature on the extraction extent of tartaric acid from aqueous phase

For the stabilization of the equilibrium between tartaric acid content in aqueous solution and in organic solution it was necessary 1 min of stirring (fig.6).

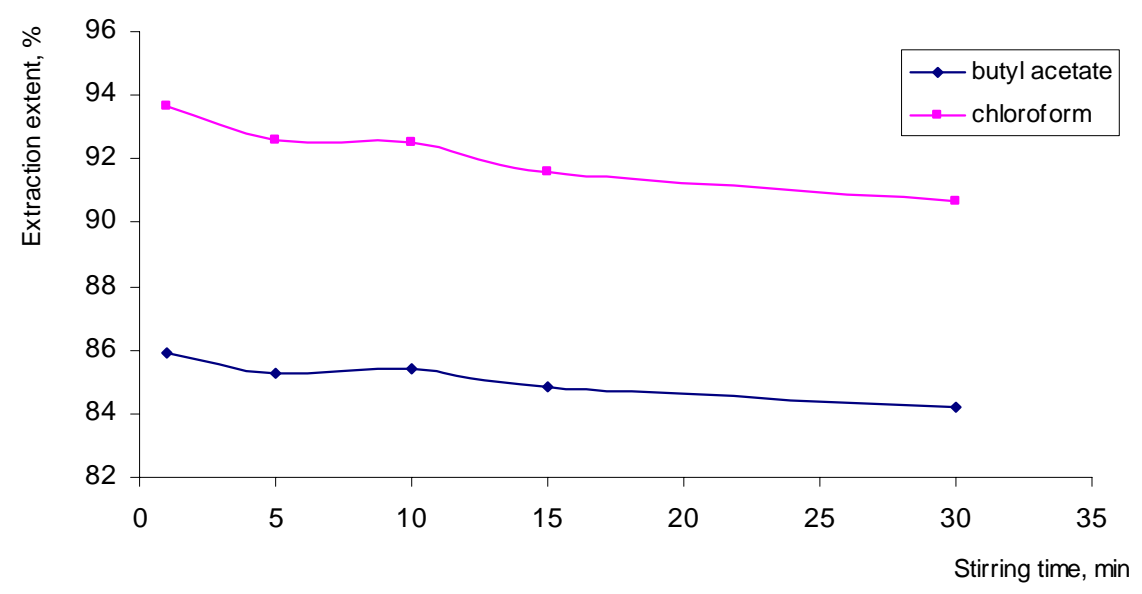

Fig. 6. The effect of the stirring time on the extraction extent of tartaric acid from aqueous solution

To identify the dependency of the reactive extraction process to the model solution $\mathrm{pH}$ values, initially was prepared a solution of tartaric acid with concentration of about $1,56 \mathrm{~g} / \mathrm{dm}^{3}$ with $\mathrm{pH}$ of 2,5 . The $\mathrm{pH}$ value of every 50 $\mathrm{cm}^{3}$ of initial solution was adjusted with concentrated solutions of $\mathrm{HCl}$ and $\mathrm{NaOH}$.

As it was shown, the efficiency of reactive extraction process decreases brusque at insignificant modifications of $\mathrm{pH}$ of the tartaric acid solution through acid values, because tartaric acid is a weak acid and does not dissociate at low values of $\mathrm{pH}$. In can be concluded that adjusting low values of $\mathrm{pH}$ by adding of hydrochloric acid to the solution of tartaric acid should lead to simultaneous separation of both acids, moreover, that $\mathrm{HCl}$ would be extracted preferentially. At intermediate values of $\mathrm{pH}$ protonation of amine is reduced and an increasing amount of undissociated tartaric acid may be separated, both through the ion-pair and H-bonding mechanisms. Experimental results from the runs in which $\mathrm{pH}$ has been adjusted with aqueous solution of $\mathrm{NaOH}$ showed that the amount of acid equimolar to the added base may be regarded as bound in form of acid sodium tartrate and, therefore, inseparable. Thus only the remaining free acid takes part in ion-exchange equilibrium. Simultaneously, the sodium hydrogen tartrate present affects the ionic strength of the solution and thus the activity of free acid [14].

\section{Conclusions}

The secondary amine Amberlite LA-2 was found to be efficient in the extraction of tartaric acid. The best physico-chemical conditions of the process have been determinated. Butyl acetate and chloroform were selected as diluents. 1-octanol was selected as modifier and its concentration in chloroform solution is $10 \%$, and in butyl acetate solution $20 \%$. The stabilized parameters of aqueous solution were: concentration of tartaric acid $-2-3 \mathrm{~g} / \mathrm{dm}^{3}$ in case of organic solutions of amine in butyl acetate, and $0,5-2 \mathrm{~g} / \mathrm{dm}^{3}$ for solutions of amine in chloroform; temperature 20-35 ${ }^{0} \mathrm{C}$; stirring time - $1 \mathrm{~min}$; $\mathrm{pH}$ value - initial $\left(\mathrm{pH}=2,5\right.$ for concentration of tartaric acid in solution $\left.1,56 \mathrm{~g} / \mathrm{dm}^{3}\right)$. 


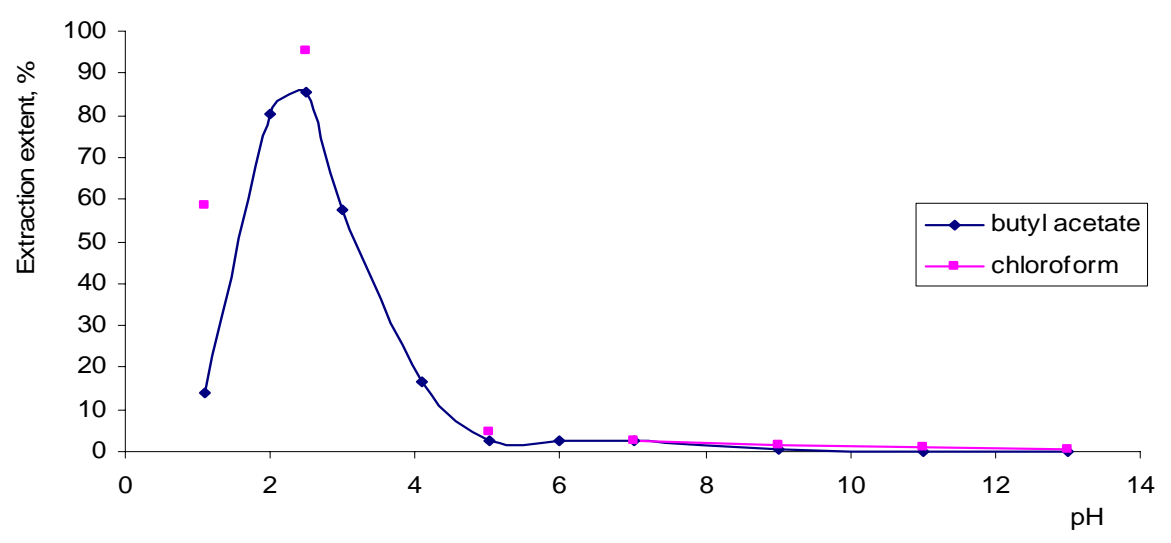

Fig. 7. The effect of initial $\mathrm{pH}$ of aqueous solution on extraction extent of tartaric acid

With a view to the practical application of the system the optimization of the reactive extraction and studies on solution of secondary wine products should be performed.

\section{References}

[1]. San Martin, M.; Bart, H. J. Recovery of Zinc from Pickling Baths with Amberlite LA-2. Influence of Modifier on the Extraction Equilibrium. Chem. Eng. Tech. 1994, 17, pp. 397-400.

[2]. Zaboska, W.; Leszko, M.; Krzymowska-Hachuka, A. Extraction of $\mathrm{Cu}(\mathrm{II})$ from Hydrochloric Acid Media by Amberlite LA-1 Hydrochloride Dissolved in 1,2-dichloroethane.Talabta, 1989, vol. 36, № 12, pp. 1295-1299.

[3]. Alguacil, F.J.; Alonso, M. Liquid-liquid Extraction of $\mathrm{Au}(\mathrm{I})$ by Amberlite LA-2 and its Application to a Polymer-Immobilized Liquid Membrane System. Gold Bulletin, 2005, 38/2, pp. 68-72.

[4]. Chatterjee, A.; Basu, S. Solvent Extraction of Silver(I) with Amberlite LA-2 Using ${ }^{110 \mathrm{~m}} \mathrm{Ag}$ as Trager. J. Radioanal. Nuclear Chem., Articles, 1992, vol. 162, № 2, pp. 259-265.

[5]. Hauer, E.; Marr, R. Liquid Extraction Processes in Biotechnology. Chem. Ing. Tech. 1991, vol. 63, № 8, pp. 809-816.

[6]. Oniscu, C.; Mereuța, A.; Caşcaval, D.; Duca, Gh. Selective Separation of Organic Oxyacids from Aqueous Phase by Reactive Extraction. Roum. Biotechnol. Lett. 2002, vol. 7, № 5, pp. 933-940.

[7]. Caşcaval, D.; Oniscu, C.; Dumitraşcu, A.; Chichirău, Al.; Toma, L. Extracția selectivă a acizilor carboxilici din lichidul rezultat de la fermentația citrică. Revista de chimie. 1998, 49, № 1.

[8]. Oniscu, C.; Caşcaval, D. Studies on Separations of Biosynthesis Products by Reactive Extraction. Roum. Biotechnol. Lett. 1996, vol. 1, № 1, pp. 23-33.

[9]. Caşcaval, D.; Tudose, R.; Oniscu, C. Reactive Extraction of Dicarboxylic Acids Selective Extraction. Hung. J. Ind. Chem. Veszprém. 1997, vol. 25, pp. 245-248.

[10]. Caşcaval, D.; Oniscu, C. Comparative Study of Some Monocarboxylic Acids I. Correlations for mass flow. Hung. J. Ind. Chem. Veszprém. 2000, vol. 28, pp. 99-103.

[11]. Juang, R. S.; Huang, W. T. Equilibrium Studies on the Extraction of Citric Acid from Aqueous Solutions with Tri-n-octylamine. J. Chem. Eng. Japan. 1994, vol. 27, № 4, pp. 498-504.

[12]. Malmary, G. H.; Mourgues, J. F.; Bakti, J.; Conte, T. S.; Achour, D.; Smagghe, F. J.; Molinier, J. R. Partition Coefficients of Tartaric and Malic Acids between Dilute Aqueous Solution and Amine Extractants Dissolved in Various Diluents. J. Chem. Eng. 1993, 38, pp. 537-539.

[13]. Kyuchoukov, G.; Labbaci, Ab.; Albet, J.; Molinier, J. Simultaneous Influence of Active and "Inert" Diluents on Extraction of Lactic Acid by Means of Tri-n-octylamine (TOA) and Tri-iso-octylamine (TIOA). Ind. Eng. Chem. Res. 2005, page est. 7,9.

[14]. Tomovska, R.; Poposka, F.; Heyberger Al.; Prochazka, J. pH-Dependence of Tartaric Acid Extraction. Chem. Biochem. Eng. Q. 1999, vol. 13, № 4, pp. 185-190.

[15]. Eyal, A. M.; Canari R. pH Dependence of Carboxylic and Mineral Acid Extraction by Amine-Based Extractants: Effects of $\mathrm{pK}_{\mathrm{a}}$, Amine Basicity, and Diluent Properties. Ind. Eng. Chem. Res. 1995, vol. 34, № 5, pp. $1789-1798$.

[16]. Razuvaev, N.I. Complexnaya pererabotka vtoricnih productov vinodelia. 1975, Moscova.

[17]. Juang, R. S.; Huang, R. H. Comparison of Extraction Equilibria of Succinic and Tartaric Acids from Aqueous Solutions with Tri-n-octylamine. Ind. Eng. Chem. Res. 1996, vol. 35, № 6, 1944-1950. 